\title{
FINITE ELEMENT ANALYSIS OF SUPERPLASTIC BLOW-FORMING OF Ti-6Al-4V SHEET INTO CLOSED ELLIP-CYLINDRICAL DIE
}

\author{
Chen, D.-C.; Chen, W.-J.; Lin, J.-Y.; Jheng, M.-W. \& Chen, J.-M. \\ Department of Industrial Education and Technology, \\ National Changhua University of Education, Changhua 500, Taiwan, R.O.C. \\ E-Mail: dcchen@cc.ncue.edu.tw
}

\begin{abstract}
Utilizing commercial DEFORM ${ }^{\mathrm{TM}}$ 3D finite element (FE) software, this study performs a series of numerical simulations to investigate the superplastic blow-forming of Ti-6Al-4V titanium alloy into a closed ellip-cylindrical die. In performing the simulations, it is assumed that the die is a rigid body and the titanium alloy sheet is a rigid-plastic material with homogeneous and isotropic properties. The simulations focus specifically on the respective effects of the shear friction factor, the die entry radius, the die height and the die's short-axis length on the thickness, effective stress, effective strain and critical damage distributions within the blow-formed product. Overall, the simulation results confirm the suitability of the DEFORM $^{\mathrm{TM}}$ 3D software for modelling the superplastic blow-forming of Ti-6Al-4V titanium alloy.

(Received in March 2009, accepted in September 2009. This paper was with the authors 2 months for 1 revision.)
\end{abstract}

Key Words: Finite Element Analysis, Superplastic Blow-Forming, Titanium Alloy, Ellip-Cylindrical Die

\section{INTRODUCTION}

The term 'superplasticity' describes the capability of certain polycrystalline materials such as $8090 \mathrm{Al}-\mathrm{Li}$ alloy, Ti-6Al-4V alloy, and so forth, to undergo extensive tensile plastic deformation prior to failure under specific temperature and strain-rate conditions. The characteristics of superplasticity, namely a low flow stress and a large elongation, have led to the development of a variety of 'superplastic forming' (SPF) processes such as forging, extrusion, blow-forming, and so on (Miller and White [1]; Al-Naib and Duncan [2]). Hwang et al. [3-4] utilized commercial DEFORM ${ }^{\mathrm{TM}} \mathrm{FE}$ software to investigate the pressurization profile and sheet thickness distribution of $8090 \mathrm{Al}-\mathrm{Li}$ sheets blow-formed into closed ellip-cylindrical and rectangular dies. A pressure control algorithm is proposed to keep the maximum stain rate in the deformation zone of the sheet equal to the target value. Senthil Kumar et al. [5] investigated the superplastic deformation behaviour of AA7475 aluminium alloy during its blow-forming into a circular die and compared the results obtained using a simple theoretical model with those generated by ABAQUS FE code. Utilizing MARC simulation software, Morsy and Manabe [6] confirmed the validity of the material characteristics and stress-strain rate relationship obtained from multi-dome tests, and showed that the multi-dome test was applicable not only to simple processes such as free bulge-forming, but also to more complex processes such as rectangular box forming. Hwang et al. [7] developed a mathematical model based upon the finite-difference method to investigate the plastic deformation behaviour of alloy sheets during blow-forming into a closed conical die. It was shown that the theoretical predictions for the respective effects of 
the die entry radius, the friction coefficient, and the inclination angle of the die on the pressurization profile, forming time and thickness distribution were in good agreement with the experimental results.

Bonet et al. [8] proposed various pressure control algorithms for FE simulations of SPF processes. Kim et al. [9] presented a combined FEA / optimization scheme for predicting the initial blank thickness distribution required to achieve a uniform final thickness in superplastic blow-formed products. Huang et al. [10] performed a series of experimental trials to validate the processing conditions predicted by ABAQUS FE simulations for optimizing the sheet thickness distribution in superplastic forming processes. Yarlagadda et al. [11] performed FE simulations of the superplastic forming of Al-Ti alloys and used the results obtained for the deformed shape, the stress-strain distribution and the thickness evolution across the facets of the fully formed surface, respectively, to optimize the processing conditions and to predict the forming time. Hambli et al. [12] presented 2D and 3D finite element models for predicting the optimum pressure cycle law, the deformed shape, the strain rate distribution and the thickness evolution during superplastic forming processes. The validity of the pressure prediction algorithm used in the numerical solution procedure was confirmed by comparing the numerical results with the experimental observations.

Verma and Kim [13] investigated and understand the effect of $\mathrm{Cu}$ additions on both elevated temperature formability and ambient temperature mechanical properties of AA5083 alloy. A detailed FE analysis of superplastic gas-blow forming was carried out using a modified microstructure-based constitutive model that accounts for grain growth and cavitation by Nazzal et al. [14]. Wu et al. [15] studied an analysis of cavitation characteristics of a SP5083 Al alloy through usage of blow forming. Sorgente et al. [16] analyzed the forming behaviour of a commercial AZ31 Mg alloy sheet at elevated temperature both in free bulging and in closed die tests.

In a previous study (Chen et al., [17-18]), the current group utilized the Taguchi design method to identify the processing parameters required to optimize the thickness distribution of Ti-6Al-4V titanium alloy following its superplastic blow-forming into an ellip-cylindrical die, and simulated the superplastic blow-forming of same alloy sheet into triangular, square and conical awl-shaped dies. In the present study, DEFORM ${ }^{\mathrm{TM}}$ 3D FE software is used to investigate the plastic deformation behaviour of Ti-6Al-4V alloy sheet blow-formed into a closed ellip-cylindrical die. The simulations focus principally on the respective effects of the shear friction factor, the die entry radius, the die height and the length of the die's short axis on the thickness, effective stress, effective strain and critical damage characteristics of the formed sheet.

\section{FINITE-ELEMENT FORMULATION}

According to Kim and Yang [19], the FE formulation for rigid-plastic deformation in a material subject to work hardening has the form

$$
\int_{V^{w}}\left(\bar{\sigma}+\alpha \Delta t \dot{\bar{\varepsilon}} H^{\prime}\right) \delta \dot{\bar{\varepsilon}} d V+K \int_{V^{w}} \dot{\varepsilon}_{v} \delta \dot{\varepsilon}_{v} d V-\int_{S_{f}^{w}}\left(f_{i}+\alpha \Delta f_{i}\right) \delta v_{i} d S=0,
$$

where $\bar{\sigma}=\sqrt{(3 / 2) \sigma_{i j}^{\prime} \sigma_{i j}^{\prime}}, \dot{\bar{\varepsilon}}=\sqrt{(2 / 3) \dot{\varepsilon}_{i j} \dot{\varepsilon}_{i j}}$ and $\dot{\varepsilon}_{v}=\dot{\varepsilon}_{i i}$. Additionally, $K, \sigma_{i j}^{\prime}, H^{\prime}$ and $\alpha$ are the penalty constant, the deviatoric stress, the strain-hardening rate and the work-hardening constant $(0 \leq \alpha \leq 1)$, respectively, while $V^{w}$ and $S^{w}$ are the volume and tractional boundary surface of the workpiece, respectively.

The DEFORM ${ }^{\mathrm{TM}}$ 3D FE simulations performed in this study are based on a flow formulation approach using an updated Lagrangian procedure. The nonlinear equations in the FE software are solved using a combined direct iteration method / Newton-Raphson scheme. 
In the solution procedure, the direct iteration method is used to generate a suitable initial estimate, and the Newton-Raphson method is then applied to obtain a rapid convergence from this initial estimate to the final solution. The iterative solution procedure terminates when the following conditions are achieved: a velocity error norm of $\|\Delta \mathbf{v}\| /\|\mathbf{v}\| \leq 0.005$ and a force error norm of $\|\Delta F\| /\|F\| \leq 0.05$, where $\|\mathbf{v}\|$ is $\left(\mathbf{v}^{T} \mathbf{v}\right)^{1 / 2}$.

The deformation behaviour of a superplastic alloy is governed by the relationship between the von Mises equivalent stress and the equivalent strain rate, and is generally expressed as follows:

$$
\bar{\sigma}=K \dot{\bar{\varepsilon}}^{m s},
$$

where $K$ is the material coefficient, and includes the combined effect of both the equivalent strain and the grain size; and $m s$ is the strain-rate sensitivity.

To express the lubricity at the interface between the ellip-cylindrical die and Ti-6Al-4V alloy sheet, the constant shear friction $\tau_{s}=m k$ is adopted, where $k$ is the yield shear stress of the deforming material, and $m$ is the friction factors $(0 \leq m \leq 1)$. The friction factors $m$ between the Ti-6Al-4V alloy sheet and ellip-cylindrical die is determined by the so called ring compression test.

\section{RESULTS AND DISCUSSION}

In simulating the superplastic blow-forming of the Ti-6Al-4V alloy sheet, the following assumptions are made: (1) the ellip-cylindrical die is a rigid body; (2) the titanium alloy sheet is a rigid-plastic material with homogeneous and isotropic properties; and (3) the friction factor between the titanium sheet and the ellip-cylindrical die remains constant throughout the blow-forming process. Fig. 1 presents the stress-strain relationship for the Ti-6Al-4V titanium alloy at a temperature of $1000^{\circ} \mathrm{C}$ and a strain rate of $0.1 \mathrm{~s}^{-1}$. As shown, the maximum flow stress ( 42 MPa) occurs at a strain of 0.5 . In performing the present simulations, the initial sheet thickness $(t)$, the long axis of the die $(a)$, the root radius of the die $(r)$, the processing temperature $(T)$ and the strain rate are all assigned constant values (see Table I). However, as shown in Table II, the values assigned to the short-axis length of the die $(b)$, the die height $(h)$, the die entry radius $(R)$, and the shear friction factor $(m)$ vary from one simulation to the next.

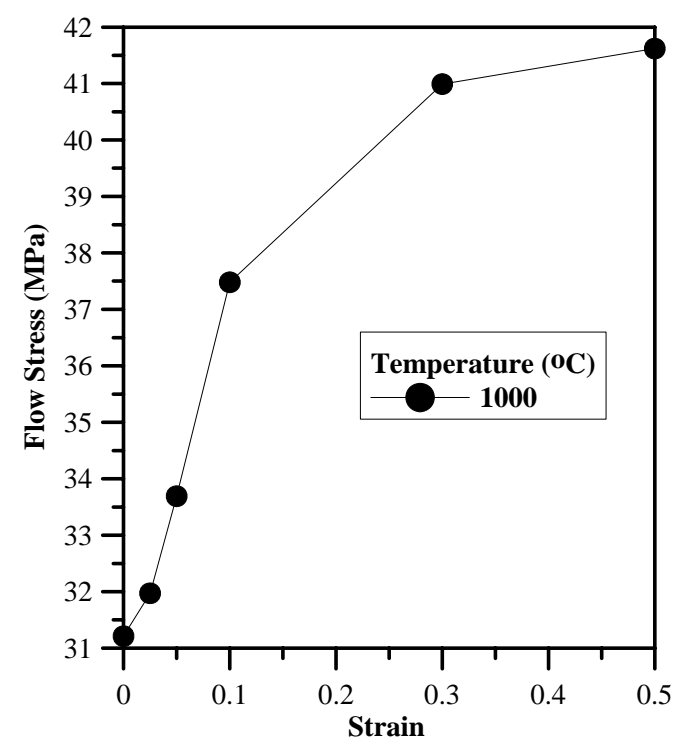

Figure 1: Stress-strain relationship for Ti-6Al-4V alloy (strain rate $=0.1 \mathrm{~s}^{-1}$ ). 
Chen, Chen, Lin, Jheng, Chen: Finite Element Analysis of Superplastic Blow-Forming of ...

Table I: Constant parameters in superplastic blow-forming simulations.

\begin{tabular}{|c|c|c|c|c|c|}
\hline Material & $\begin{array}{c}\text { Thickness } \\
\text { of sheet }(t)\end{array}$ & $\begin{array}{c}\text { Long axis } \\
\text { of the die }(a)\end{array}$ & $\begin{array}{c}\text { Die root } \\
\text { radius }(r)\end{array}$ & $\begin{array}{c}\text { Temperature } \\
(T)\end{array}$ & $\begin{array}{c}\text { Strain } \\
\text { rate }\end{array}$ \\
\hline Ti-6Al-4V & $1.5 \mathrm{~mm}$ & $40 \mathrm{~mm}$ & $2 \mathrm{~mm}$ & $1000^{\circ} \mathrm{C}$ & $0.1(1 / \mathrm{s})$ \\
\hline
\end{tabular}

Fig. 2 presents the meshed models of the Ti-6Al-4V alloy sheet and ellip-cylindrical die at steps 1, 8, 12, 22 and 47 of the simulated blow-forming process. Note that due to the inherent symmetry of the ellip-cylindrical die, only one-quarter of the sheet / die model (comprising 8000 3D elements) is presented here. As shown, in simulating the blow-forming process, the following geometry parameters and experimental conditions were assumed: $t$ (thickness of sheet) $=1.5 \mathrm{~mm}, a$ (long axis of the die) $=40 \mathrm{~mm}, b$ (short axis of the die) $=20 \mathrm{~mm}, R$ (die entry radius) $=5 \mathrm{~mm}, r$ (die root radius) $=2 \mathrm{~mm}, h$ (die height) $=10 \mathrm{~mm}, m$ (shear friction factor $)=0.5, T$ (temperature of Ti-6Al-4V alloy sheet) $=1000^{\circ} \mathrm{C}$, and strain rate $=0.1 \mathrm{~s}^{-1}$. In addition, an assumption was made that the titanium sheet was firmly attached to the periphery of the die such that no metal flowed from the periphery regions of the sheet into the die cavity during the forming process.

Table II: Variable parameters in superplastic blow-forming simulations.

\begin{tabular}{|c|c|c|c|c|}
\hline Factors & $\begin{array}{l}\text { Short axis } \\
\text { (b) }\end{array}$ & $\begin{array}{l}\text { Die height } \\
(h)\end{array}$ & $\begin{array}{l}\text { Die entry } \\
\text { radius }(R)\end{array}$ & $\begin{array}{l}\text { Shear friction } \\
\text { factor }(m)\end{array}$ \\
\hline 1 & 20 & 10 & 5 & 0.5 \\
\hline 2 & 20 & 10 & 5 & 0.2 \\
\hline 3 & 20 & 10 & 5 & 0.05 \\
\hline 4 & 20 & 10 & 7 & 0.5 \\
\hline 5 & 20 & 10 & 7 & 0.2 \\
\hline 6 & 20 & 10 & 7 & 0.05 \\
\hline 7 & 20 & 9 & 5 & 0.5 \\
\hline 8 & 20 & 9 & 5 & 0.2 \\
\hline 9 & 20 & 9 & 5 & 0.05 \\
\hline 10 & 20 & 9 & 7 & 0.5 \\
\hline 11 & 20 & 9 & 7 & 0.2 \\
\hline 12 & 20 & 9 & 7 & 0.05 \\
\hline 13 & 30 & 10 & 5 & 0.5 \\
\hline 14 & 30 & 10 & 5 & 0.2 \\
\hline 15 & 30 & 10 & 5 & 0.05 \\
\hline 16 & 30 & 10 & 7 & 0.5 \\
\hline 17 & 30 & 10 & 7 & 0.2 \\
\hline 18 & 30 & 10 & 7 & 0.05 \\
\hline 19 & 30 & 9 & 5 & 0.5 \\
\hline 20 & 30 & 9 & 5 & 0.2 \\
\hline 21 & 30 & 9 & 5 & 0.05 \\
\hline
\end{tabular}


$t=1.5 \mathrm{~mm}, a=40 \mathrm{~mm}, b=20 \mathrm{~mm}, R=5 \mathrm{~mm}, r=2 \mathrm{~mm}, h=10 \mathrm{~mm}, m=0.5, T=1000^{\circ} \mathrm{C}$, Strain rate $=0.1 \mathrm{~s}^{-1}$

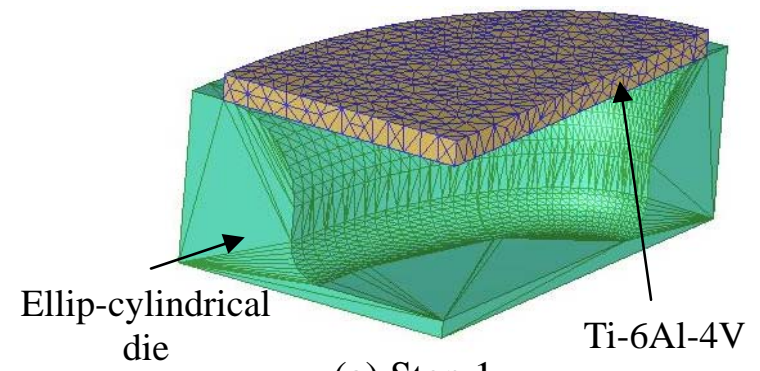

(a) Step 1

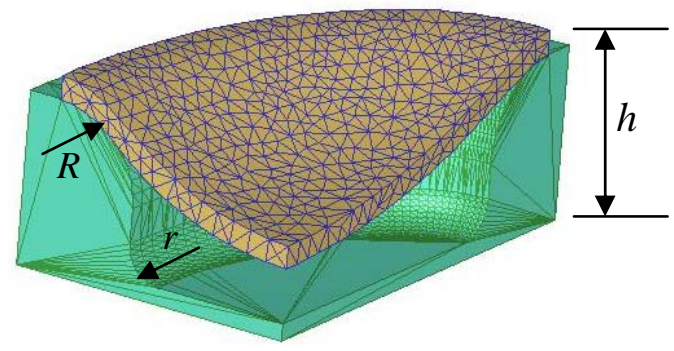

(b) Step 8

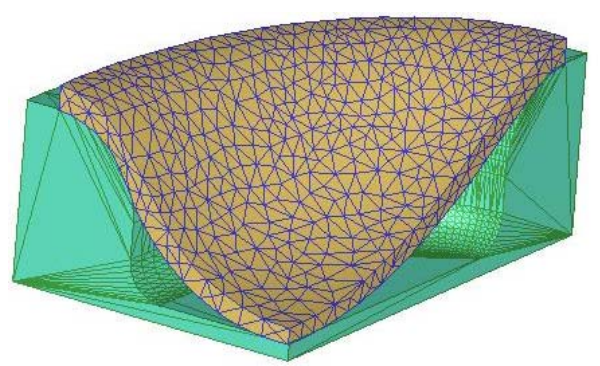

(c)Step 12

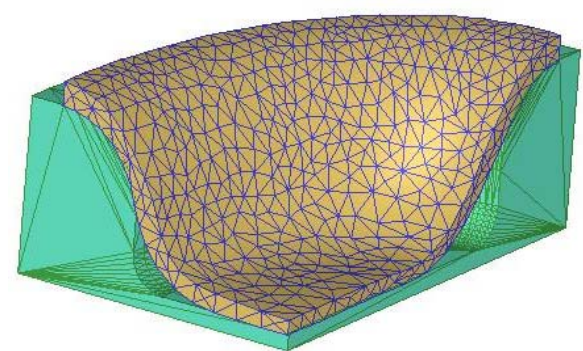

(d) Step 22

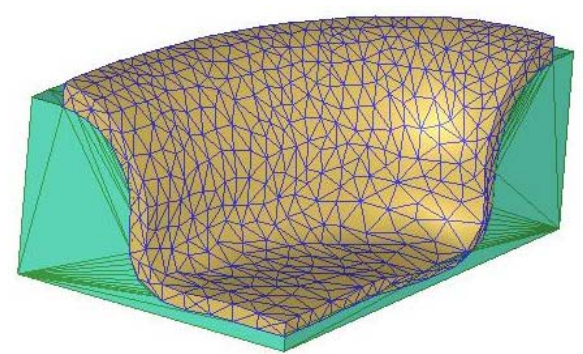

(e) Step 47

Figure 2: Finite element model of titanium sheet and ellip-cylindrical die. 
The modelling formulations of various ductility damage values were reported by Klocke et al. [20]. The damage induced in the superplastic blow-forming of the present titanium alloy sheet is evaluated using the following normalized C\&L criterion:

$$
\int_{0}^{\bar{\varepsilon}_{f}} \frac{\sigma_{\max }}{\bar{\sigma}} d \bar{\varepsilon}=C_{d},
$$

where $\sigma_{\max }$ is the maximum ductile stress, $\bar{\varepsilon}_{f}$ is the effective fracture strain, and $C_{d}$ is the damage value of the material.

Fig. 3 illustrates the distributions of the damage, effective strain and effective stress, respectively, within the titanium alloy sheet following superplastic blow-forming under conditions of: $t=1.5 \mathrm{~mm}, a=40 \mathrm{~mm}, b=30 \mathrm{~mm}, R=5 \mathrm{~mm}, r=2 \mathrm{~mm}, h=9 \mathrm{~mm}, m=0.5, T$ $=1000^{\circ} \mathrm{C}$, and a strain rate of $0.1 \mathrm{~s}^{-1}$. Figs. 3(a) and 3(b) reveal that the maximum damage and maximum effective strain are located in the regions of the titanium sheet close to the entry radius of the die. By contrast, Fig. 3(c) shows that the maximum effective stress is distributed uniformly over the entire surface of the ellip-cylindrical product.

Fig. 4 shows the general product appearance, the damage distribution, the effective strain distribution and the effective stress distribution following superplastic blow-forming under conditions of: $t=1.5 \mathrm{~mm}, a=40 \mathrm{~mm}, b=20 \mathrm{~mm}, R=7 \mathrm{~mm}, r=2 \mathrm{~mm}, h=10 \mathrm{~mm}, m=0.5$, $T=1000^{\circ} \mathrm{C}$, and a strain rate of $0.1 \mathrm{~s}^{-1}$. The results reveal that under these modified processing conditions, the maximum damage and effective strain are induced near the root radius of the die (see Figs. 4(a) and 4(b), respectively). However, the maximum effective stress is once again distributed uniformly over the entire surface of the blow-formed product.

Fig. 5 illustrates the variation of the titanium alloy thickness following blow-forming under conditions of $t=1.5 \mathrm{~mm}, a=40 \mathrm{~mm}, b=30 \mathrm{~mm}, R=5 \mathrm{~mm}, r=2 \mathrm{~mm}, h=9 \mathrm{~mm}, m=$ $0.5, T=1000^{\circ} \mathrm{C}$, and a strain rate of $0.1 \mathrm{~s}^{-1}$. As shown, the maximum sheet thickness $(1.42 \sim$ $1.46 \mathrm{~mm}$ ) occurs near the entry radius region of the die, while the minimum sheet thickness $(0.68 \sim 1.02 \mathrm{~mm})$ occurs near the root radius region of the die.

Fig. 6 presents a mesh model showing the fracture of the titanium alloy sheet following blow-forming under conditions of $t=1.5 \mathrm{~mm}, a=40 \mathrm{~mm}, b=30 \mathrm{~mm}, R=5 \mathrm{~mm}, r=2 \mathrm{~mm}, h$ $=10 \mathrm{~mm}, m=0.2, T=1000^{\circ} \mathrm{C}$, and a strain rate of $0.1 \mathrm{~s}^{-1}$. The results indicate that under these particular blow-forming conditions, the flow stress induced within the titanium sheet exceeds the yield strength of the titanium alloy and causes the alloy to fracture.

Table III summarizes the thickness of the titanium alloy sheet at various positions of the ellip-cylindrical product following blow-forming under each of the 21 conditions given in Table II. As shown, both the initial pressure and the pressure increase applied after 5 steps in the simulation process are assigned values of $1 \mathrm{MPa}$, 1.5 $\mathrm{MPa}$ or $2 \mathrm{MPa}$. Overall, the results reveal that the thickness of the titanium sheet varies in the range $1.22 \sim 1.37 \mathrm{~mm}$ in the long-axis region of the entry radius part of the die, $0.49 \sim 0.96 \mathrm{~mm}$ in the long-axis region of the root radius part of the die, $0.71 \sim 1.30 \mathrm{~mm}$ in the short-axis region of the entry radius part of the die, and $0.47 \sim 1.21 \mathrm{~mm}$ in the central region of the die. In other words, the results confirm that the minimum thickness of the ellip-cylindrical product occurs in the region closest to the die root radius. 
$t=1.5 \mathrm{~mm}, a=40 \mathrm{~mm}, b=30 \mathrm{~mm}, R=5 \mathrm{~mm}, r=2 \mathrm{~mm}, h=9 \mathrm{~mm}, m=0.5, T=1000^{\circ} \mathrm{C}$, Strain rate $=0.1 \mathrm{~s}^{-1}$

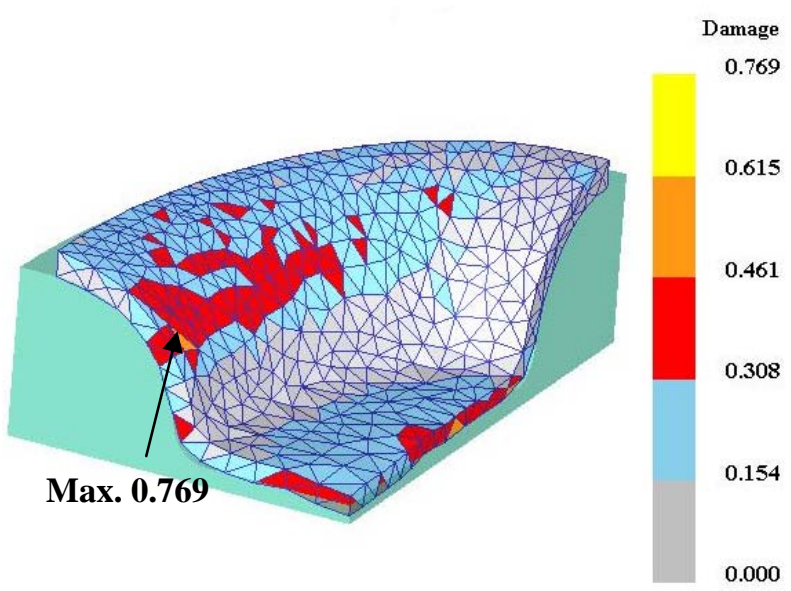

(a) Damage

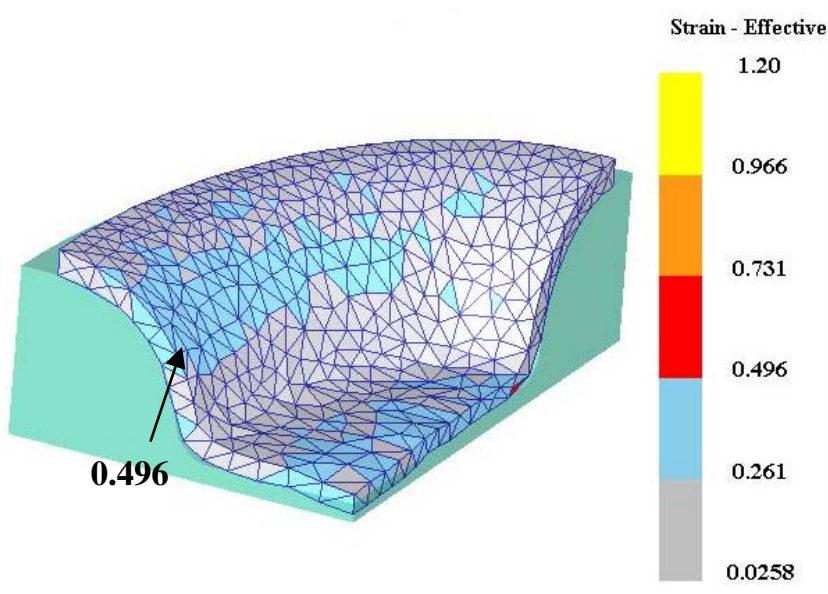

(b) Effective strain

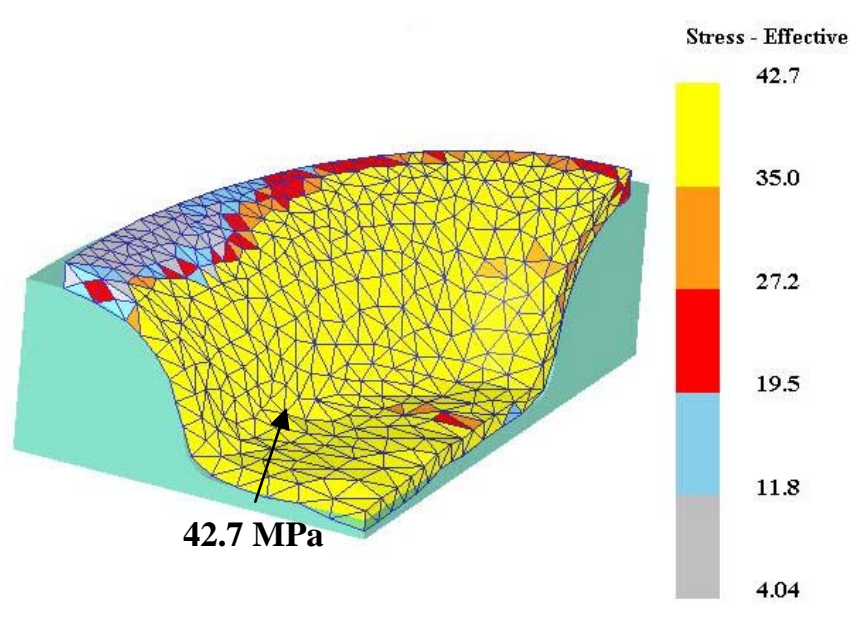

(c) Effective stress

Figure 3: Distribution of damage, effective strain and effective stress in blow-formed Ti-6Al-4V ellip-cylindrical product (one-quarter die). 
$t=1.5 \mathrm{~mm}, a=40 \mathrm{~mm}, b=20 \mathrm{~mm}, R=7 \mathrm{~mm}, r=2 \mathrm{~mm}, h=10 \mathrm{~mm}, m=0.5, T=1000^{\circ} \mathrm{C}$, Strain rate $=0.1 \mathrm{~s}^{-1}$

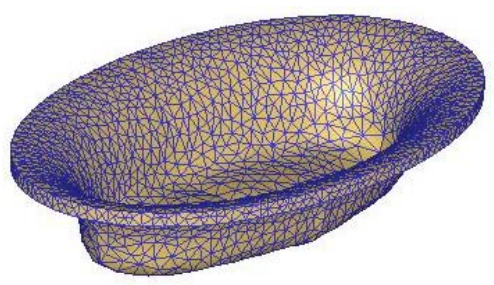

(a) Appearance of product

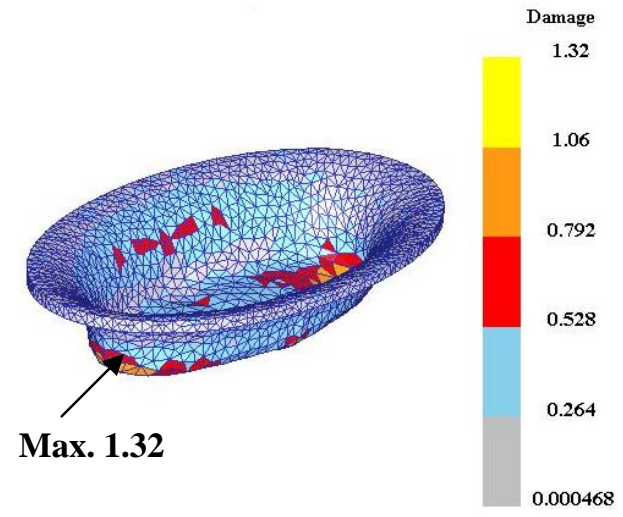

(b) Damage

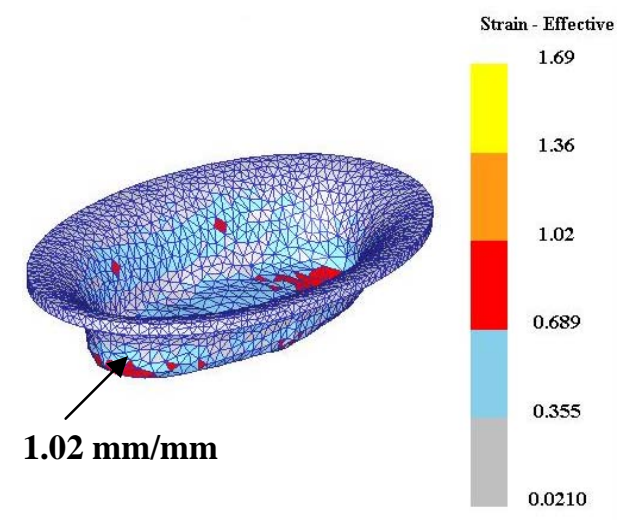

(c) Effective strain

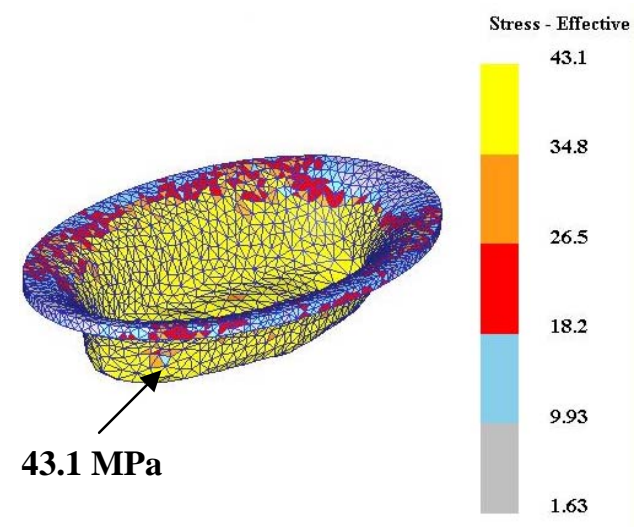

(d) Effective stress

Figure 4: Appearance and distributions of damage, effective strain and effective stress in blow-formed Ti-6Al-4V ellip-cylindrical product (full die). 
$t=1.5 \mathrm{~mm}, a=40 \mathrm{~mm}, b=30 \mathrm{~mm}, R=5 \mathrm{~mm}, r=2 \mathrm{~mm}, h=9 \mathrm{~mm}, m=0.5, T=1000^{\circ} \mathrm{C}$, Strain rate $=0.1 \mathrm{~s}^{-1}$

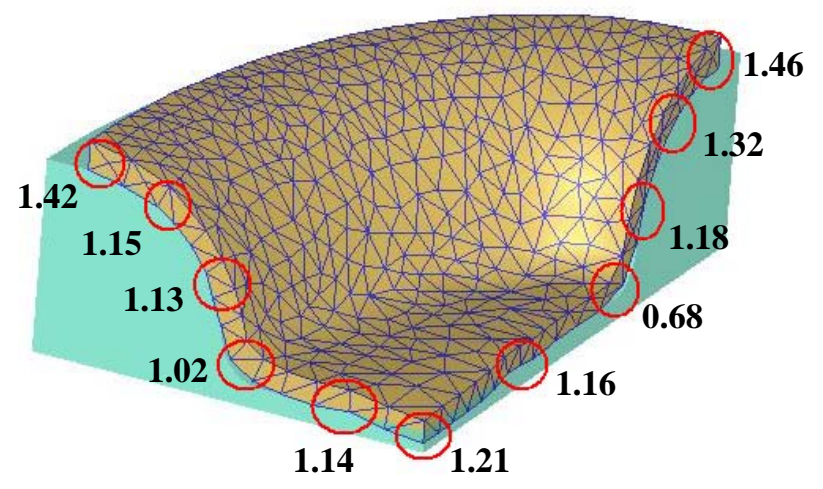

Figure 5: Distribution of ellip-cylindrical product thickness (units: mm).

$t=1.5 \mathrm{~mm}, a=40 \mathrm{~mm}, b=30 \mathrm{~mm}, R=5 \mathrm{~mm}, r=2 \mathrm{~mm}, h=10 \mathrm{~mm}, m=0.2, T=1000^{\circ} \mathrm{C}$, Strain rate $=0.1 \mathrm{~s}^{-1}$

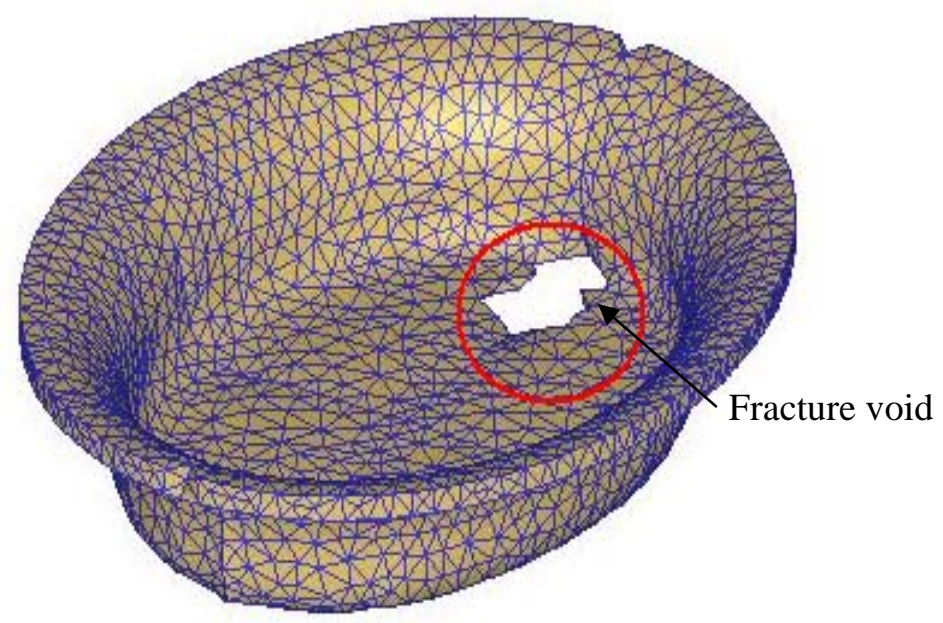

Figure 6: Fracture of ellip-cylindrical product.

\section{CONCLUSIONS}

This study has utilized DEFORM ${ }^{\mathrm{TM}}$ 3D FE software to investigate the plastic deformation behaviour of Ti-6Al-4V titanium alloy during its superplastic blow-forming into a closed ellip-cylindrical die. The simulations focus principally on the respective effects of the shear friction factor, the die entry radius, the die height and the length of the die's short axis on the thickness, effective stress, effective strain and critical damage characteristics of the formed sheet. The simulation results support the following major conclusions: (1) the maximum effective stress is distributed uniformly over the entire surface of the ellip-cylindrical product; (2) the minimum sheet thickness is induced in the region of the ellip-cylindrical product close to the root radius region of the die; and (3) in the event that the flow stress induced within the blow-forming process exceeds the yield strength of the Ti-6Al-4V alloy, the ellip-cylindrical product fractures in the flat base region. Overall, the simulation results confirm the suitability of the FE software for modelling the superplastic blow-forming of Ti-6Al-4V titanium alloy. 
Chen, Chen, Lin, Jheng, Chen: Finite Element Analysis of Superplastic Blow-Forming of ...

Table III: Summary of ellip-cylindrical product thickness for all considered simulation conditions.

\begin{tabular}{|c|c|c|c|c|c|c|}
\hline Factors & $\begin{array}{c}\text { Initial } \\
\text { Pressure } \\
\text { (MPa) }\end{array}$ & $\begin{array}{c}\text { Increasing } \\
\text { pressure } \\
\text { after 5 steps } \\
\text { (MPa) }\end{array}$ & $\begin{array}{c}\text { Thickness } \\
\text { of die entry } \\
\text { radius (mm) } \\
\text { (long axis) }\end{array}$ & $\begin{array}{c}\text { Thickness } \\
\text { of die root } \\
\text { radius (mm) } \\
\text { (long axis) }\end{array}$ & $\begin{array}{c}\text { Thickness } \\
\text { of die entry } \\
\text { radius (mm) } \\
\text { (short axis) }\end{array}$ & $\begin{array}{c}\text { Thickness of } \\
\text { central } \\
\text { position (mm) }\end{array}$ \\
\hline 1 & 2 & 2 & 1.32 & 0.64 & 0.95 & 0.82 \\
\hline 2 & 2 & 2 & 1.30 & 0.57 & 0.82 & 1.00 \\
\hline 3 & 2 & 2 & 1.32 & 0.75 & 0.71 & 0.93 \\
\hline 4 & 2 & 2 & 1.26 & 0.50 & 1.17 & 0.92 \\
\hline 5 & 2 & 2 & 1.27 & 0.57 & 1.06 & 0.88 \\
\hline 6 & 2 & 2 & 1.27 & 0.65 & 0.98 & 0.87 \\
\hline 7 & 2 & 2 & 1.25 & 0.84 & 0.98 & 1.07 \\
\hline 8 & 2 & 2 & 1.25 & 0.76 & 1.05 & 0.68 \\
\hline 9 & 2 & 2 & 1.30 & 0.96 & 0.88 & 0.48 \\
\hline 10 & 2 & 2 & 1.23 & 0.78 & 1.05 & 0.47 \\
\hline 11 & 2 & 2 & 1.22 & 0.76 & 1.04 & 0.69 \\
\hline 12 & 2 & 2 & 1.30 & 0.89 & 0.99 & 0.63 \\
\hline 13 & 2 & 2 & 1.35 & 0.56 & 1.11 & 1.08 \\
\hline 14 & 1.5 & 1.5 & 1.34 & 0.56 & 1.30 & 1.07 \\
\hline 15 & 1.5 & 1.5 & 1.37 & 0.51 & 1.19 & 1.02 \\
\hline 16 & 1 & 1 & 1.22 & 0.49 & 1.24 & 1.16 \\
\hline 17 & 1 & 1 & 1.28 & 0.57 & 1.25 & 1.15 \\
\hline 18 & 1 & 1 & 1.29 & 0.61 & 1.21 & 1.03 \\
\hline 19 & 1.5 & 1.5 & 1.32 & 0.68 & 1.15 & 1.21 \\
\hline 20 & 1.5 & 1.5 & 1.34 & 0.72 & 1.20 & 1.19 \\
\hline 21 & 1.5 & 1.5 & 1.37 & 0.79 & 1.21 & 1.03 \\
\hline & & & & & & \\
\hline
\end{tabular}

\section{REFERENCES}

[1] Miller, Q. S.; White, J. (1988). Chapter in: Superplasticity in Aerospace, Heikkenen, H. C.; McNelley, T. R. (Eds.), AIME, Warrendate, PA, Vol. 211

[2] Al-Naib, T. Y. M.; Duncan, J. L. (1970). Superplastic metal forming, International Journal of Mechanical Sciences, Vol. 12, 463-477

[3] Hwang, Y. M.; Lay, H. S.; Huang, J. C. (2002). Study on superplastic blow-forming of 8090 Al-Li sheets in an ellip-cylindrical closed-die, International Journal of Machine Tools \& Manufacture, Vol. 42, 1363-1372

[4] Hwang, Y. M.; Lay, H. S. (2003). Study on superplastic blow-forming in a rectangular closed-die, Journal of Materials Processing Technology, Vol. 140, 426-431

[5] Senthil Kumar, V. S.; Viswanathan, D.; Natarajan, S. (2006). Theoretical prediction and FEM analysis of superplastic forming of AA7475 aluminum alloy in a hemispherical die, Journal of Materials Processing Technology, Vol. 173, 247-251

[6] Morsy, A. W. E.; Manabe, K. I. (2002). FE simulation of rectangular box forming using material characteristics from the multi-dome forming test, Journal of Materials Processing Technology, Vol. 125-126, 772-777 
[7] Hwang, Y. M.; Yang, J. S.; Chen, T. R.; Huang, J. C.; Wu, W. U. (1998). Analysis of superplastic blow-forming in a conical closed die, International Journal of Mechanical Sciences, Vol. 40, No. 9, 867-885

[8] Bonet, J.; Wood, R. D.; Collins, R. (1994). Pressure-control algorithms for the numerical simulation of superplastic forming, International Journal of Mechanical Sciences, Vol. 36, No. 4, 297-309

[9] Kim, Y. H.; Lee, J. M.; Hong, S. S. (2001). Optimal design of superplastic forming processes, Journal of Materials Processing Technology, Vol. 112, 166-173

[10] Huang, A.; Lowe, A.; Cardew-Hall, M. J. (2001). Experimental validation of sheet thickness optimization for superplastic forming of engineering structures, Journal of Materials Processing Technology, Vol. 112, 136-143

[11] Yarlagadda, P. K. D. V.; Gudimetla, P.; Adam, C. (2002). Finite element analysis of high strain rate superplastic forming (SPF) of Al-Ti alloys, Journal of Materials Processing Technology, Vol. 130-131, 469-476

[12] Hambli, R.; Potiron, A.; Guerin, F.; Dumon, B. (2001). Numerical pressure prediction algorithm of superplastic forming processes using 2D and 3D models, Journal of Materials Processing Technology, Vol. 112, 83-90

[13] Verma, R.; Kim, S. (2007). Superplastic behavior of copper-modified 5083 aluminum alloy, Journal of Materials Engineering and performance, Vol. 16, 185-191

[14] Nazzal, M. A.; Khraisheh, M. K.; Darras, B. M. (2004). Finite element modeling and optimization of superplastic forming using variable strain rate approach, Journal of Materials Engineering and performance, Vol. 13, 691-699

[15] Wu, H. Y.; Perng, J. Y.; Shis, S. H.; Chiu, C. H.; Lee, S.; Wang, J. Y. (2006). Cavitation characteristics of a superplastic $5083 \mathrm{Al}$ alloy during gas blow forming, Journal of Materials Science, Vol. 41, 7446-7453

[16] Sorgente, D.; Scintilla L. D.; Palumbo, G.; Tricarico, L. (2010). Blow forming of AZ31 magnesium alloy at elevated temperatures, International Journal of Material Forming, Vol. 3, No. $1,13-19$

[17] Chen, D. C.; Lin, J. Y.; Jheng, M. W.; Chen, J. M. (2007). Design of titanium alloy superplastic blow-forming in ellip-cylindrical die using Taguchi method, Proceedings of the $35^{\text {th }}$ International MATADOR Conference, Taipei, Taiwan, 105-109

[18] Chen, D. C.; Wang, H. N. (2008). A finite element analysis of the superplastic blow-forming in an awl-shaped die with titanium alloy, Computer Methods in Materials Science, Vol. 8, No. 3, 130-137

[19] Kim, Y. J.; Yang, D. Y. (1985). A formulation for rigid-plastic finite element method considering work-hardening effect, International Journal of Mechanical Sciences, Vol. 27, No. 7-8, 487-495

[20] Klocke, F.; Breuer, D.; Raedt, H. (2002). Prediction of Ductile Fracture in Cold Forming Processes, Proceedings of the $7^{\text {th }}$ ICTP, Advanced Technology of Plasticity, Yokohama, Japan, Vol. $1,721-726$ 